\title{
Psychoanalysis and psychoanalytic psychotherapy in the National Health Service
}

\author{
Harold Stewart Tavistock Clinic, London
}

In the brief answer that I am allowed to Dr Wilkinson's paper, I will restrict myself to a few issues touched upon. We must however differentiate psychoanalysis from psychoanalytic psychotherapy to bring clarity to the author's confusing of them, particularly in his first section. The former is a very lengthy treatment involving regular attendance at fifty-minute sessions from four to five times a week for a number of years, whereas the latter includes therapies such as individual psychotherapy which may be brief or long-term on a once or twice weekly basis, group therapy, family therapy, marital therapy, etc. They are called psychoanalytic since they have been developed from the insights and principles of psychoanalysis. The former is available to only a few patients on the National Health Service (NHS) at the London Clinic of Psychoanalysis, whereas the latter is available at the major NHS psychotherapy clinics such as the Tavistock Clinic, the Paddington Centre for Psychotherapy, and the Cassel Hospital, and in most NHS psychiatric outpatient clinics. Clearly it is only the latter that concerns us in economics and costeffectiveness in the NHS since virtually no one argues that psychoanalysis should be generally available in the health service.

If we turn to the 'research on the efficacy of psychoanalytic treatment', the author writes as though a case against them has been definitively established. In his consideration of the recent correspondence in the British Fournal of Psychiatry on What Price Psychotherapy, the views of those supporting the efficacy of psychotherapy are dismissed with the short sentence, 'Despite this, the psychotherapy lobby seems unruffled'. Is this a scientific attitude to real disagreements? As for research into psychoanalysis, the International Review of Psychoanalysis in 1985 published a lengthy study in four papers (1) of the outcome of psychoanalysis in 700 cases and of psychotherapy in 885 cases; these references quoted four previous outcome studies. Even psychoanalysts and psychotherapists want to know the value of their labours.

In his section on primary care, the author speaks of

\section{Key words}

Psychoanalysis; psychoanalytic psychotherapy; psychotherapy; National Health Service.
Balint's work with general practitioners and quotes that 'this is a form of apprenticeship in which through the seminars, the general practitioners would learn to do psychotherapy under supervision'. This is incorrect; Balint, with whom I have worked, regarded the outcome of his seminars a failure if the GP became a psychotherapist rather than a GP. His aim was to help the doctor to acquire the extra skill of psychodynamic understanding based on simple psychoanalytic principles to bring to his or her work. To speak of economics, many such GPs have the impression that the use of such understanding often results in considerable savings in the cost of expensive drugs and expensive and often unnecessary medical investigations.

In his discussions on health economics and psychotherapy, the author could equally well have been talking of organic psychiatry since in neither has there been the necessary and very difficult evaluations of costeffectiveness etc that are required for proper assessment. However, it is when we come to ethical considerations that the author's bias against psychotherapy really takes wing. From Dr Wilkinson's quoted extracts from the Foster and Sieghart reports, no reader could expect to find that in these same reports, Foster (paras 257-258) approvingiy quotes recommendations by Freud concerning the grounds for the establishment of the professions of psychoanalysis and psychotherapy, the very grounds that every reputable psychoanalytic and psychotherapeutic institute in the world uses in its practice; and Sieghart, in the same 'revealing foreword' mentioned by Wilkinson, commends the Foster report and in an appendix, even repeats the quotations of Freud's recommendations from the Foster Report. What price ethics and truth!

Dr Harold Stewart FRCPsych is Consultant Psychotherapist, Tavistock Clinic, 120 Belsize Lane, London NW3 SBA.

\section{References}

(1) Weber J, Solomon M, Bachrach H. Characteristics of $\varrho$ psychoanalytic clinic patients: report of the Columbia Psychoanalytic Center Research Project (I). International review of psychoanalysis 1985a; 12: 13-26; Weber J, Solomon 응 M, Bachrach $\mathbf{H}$. Factors associated with the outcome of psychoanalysis: report of the Columbia Psychoanalytic $\bar{\emptyset}$ Center Research Project (II). International review of $\stackrel{?}{\risingdotseq}$ 
psychoanalysis 1985b; 12: 127-141; Weber J, Solomon M, Bachrach H. Factors associated with the outcome of psychoanalysis: report of the Columbia Psychoanalytic Center Research Project (III). International review of psychoanalysis 1985c; 12: 251-262; Weber J, Solomon M,
Bachrach H. Factors associated with the outcome of psychoanalysis (clinical and methodological considerations): report of the Columbia Psychoanalytic Center Research Project (IV). International review of psychoanalysis 1985d; 12: 379-389. 